\title{
Sustainable and equitable sanitation in informal settlements of Cape Town: a common vision?
}

\author{
SM Pan ${ }^{1 *}$, NP Armitage ${ }^{1}$ and MB Van Ryneveld ${ }^{1}$ \\ 'Department of Civil Engineering, University of Cape Town, Private Bag X3, Rondebosch 7701, South Africa
}

\begin{abstract}
Sustainability and equity are two desirable but ambiguous concepts often used to describe goals for sanitation services internationally and in South Africa. Both concepts are mentioned repeatedly in policy documents and government reports. There is, however, a gap between policy and implementation, and part of the problem lies in the challenge of reconciling the pressure to deliver immediate results with a long-term vision to strive towards sustainable and equitable sanitation services. Perspectives, priorities, and barriers to sustainability and equity in implementation, recognised amongst water and sanitation sector stakeholders in Cape Town, were analysed and compared with policy documents and municipal records. The research methods included a review of municipal and national sanitation policy documents and reports, and unstructured interviews with municipal officials, development NGO workers, sanitation consultants and entrepreneurs working in Cape Town municipality. In this paper, challenges to integrating sustainability and equity principles into various stages of sanitation service development are highlighted, and preliminary recommendations for addressing challenges are made, with an emphasis on stakeholder participation.
\end{abstract}

Keywords: urban sanitation, sustainability, equity, South Africa

\section{INTRODUCTION}

In the international post-2015 Joint Monitoring Programme (JMP) agenda for water supply, sanitation and hygiene (WASH), two of the major principles emphasised are sustainability and equity of services to achieve 'universal access to safe water, sanitation and hygiene' (WHO and UNICEF, 2013). The importance of sustainable and equitable services is also acknowledged in the South African Free Basic Sanitation Implementation Strategy (DWAF, 2008). The definitions of sustainability and equity as they pertain to sanitation services are, however, applied differently in the two documents and require clarification. For the purposes of this paper, sustainable sanitation is defined similarly to the definition used by the Sustainable Sanitation Alliance (SuSanA), i.e., a sanitation system that is 'economically viable, socially acceptable, and technically and institutionally appropriate; it should protect the environment and natural resources' (SuSanA, 2014), and promote health and hygiene (Rosemarin et al., 2008). An additional sanitationspecific consideration promoted under the Bellagio Principles includes considering waste as a resource that should be managed as close as possible to the source (EAWAG and SANDEC, 2000).

Equity also requires further definition, both generally and when it pertains to sanitation. Equity is an 'ethical concept' relating to notions of 'social justice, fairness, and human rights' based on need as a foundation for the allocation of resources (Scott et al., 2012). As with sustainability, there are different dimensions to be considered such as barriers that limit access to sanitation facilities, with key considerations relating to

This paper was originally presented at the 2014 Water Institute of Southern Africa (WISA) Biennial Conference, Mbombela, 25-29 May 2014.

* To whom all correspondence should be addressed.

ฮ +2721650 5317; Fax: +27 21689 7471;

e-mail: sphpan001@myuct.ac.za gender aspects, people with disabilities, the elderly and children. There are also regional disparities in sanitation coverage, such as between rural and urban areas (Freeman et al., 2011), or between different economic groups within the same city. Sanitation coverage and levels of service in 'informal settlements' - residential areas which do not meet local authority requirements for conventional townships, often characterised by inadequate infrastructure, makeshift dwellings, and poor access to health and education facilities (PGWC, 2003) - are usually much lower than in 'formal' areas (Stats SA, 2010). The need to consider resource allocation for sanitation service provision on both a national and municipal level is an important equity consideration.

Some of the challenges with trying to ensure that sustainability and equity considerations are incorporated into sanitation services include the lack of clear, context-specific criteria within policy, the 'value-laden and political' (Movik and Mehta, 2010) nature of both sustainability and equity as concepts, as well as the tension between meeting short-term goals, e.g. increasing the number of toilets in informal areas as quickly as possible, and a long-term vision for sustainable and equitable sanitation services. Specific assessment tools for sanitation systems suggested in the literature (Table 1) often include both qualitative and quantitative indicators associated with various environmental, economic, technical, health and socio-cultural criteria (Hellström et al., 2000; Balkema et al., 2002; Kvarnström et al., 2004), but assessment of these criteria during sanitation planning is often lacking. Examining the equity of sanitation services is also inadequately addressed amidst other competing crises. In Cape Town, and other South African municipalities, the Integrated Development Plan (IDP) is a mandatory 5-year strategy document which outlines priority development areas for the city. While sustainability and equity are major themes of the IDP, when it comes to specific objectives and indicators for sanitation (and other services) used to guide and measure 
progress, both qualitative and quantitative indicators are lacking with the exception of the number of water taps and toilets provided in informal settlements (CCT, 2013a). Sustainability and equity criteria still need to be prioritised in planning sanitation services so as to go beyond a narrow focus on access ratios.
Table 1 gives examples of general sustainability indicators for sanitation systems, but who should be responsible for assessing them, and which indicators are most relevant to informal areas still needs to be determined.

The purpose of this research was to investigate challenges to incorporating sustainability and equity into sanitation services

\begin{tabular}{|c|c|c|c|}
\hline \multicolumn{4}{|c|}{$\begin{array}{l}\text { TABLE } 1 \\
\begin{array}{l}\text { Sustainability assessment criteria for sanitation services, from collection to treatment and reuse and/or disposal (after } \\
\text { Hellström et al., } 2000 \text { and Kvarnström et al., 2004) }\end{array}\end{array}$} \\
\hline Criteria & Indicator & Criteria & Indicator \\
\hline \multicolumn{2}{|l|}{ Environmental } & \multicolumn{2}{|l|}{ Technical } \\
\hline Land use & $\mathrm{m}^{2} /$ person & $\begin{array}{l}\text { System robustness: risk of failure, } \\
\text { effect of failure, structural stabil- } \\
\text { ity, robustness against extreme } \\
\text { conditions }\end{array}$ & Qualitative \\
\hline Energy & $\mathrm{MJ} /$ person & $\begin{array}{l}\text { Robustness of use: sensitivity to } \\
\text { shock loads, abuse of system }\end{array}$ & Qualitative \\
\hline Construction material & Type and volume & $\begin{array}{l}\text { Flexibility/adaptability (to differ- } \\
\text { ent conditions/user groups) }\end{array}$ & Qualitative \\
\hline Chemicals & Type and volume & Security & Qualitative \\
\hline $\begin{array}{l}\text { Fresh water used } \\
(\mathrm{O} \& \mathrm{M})\end{array}$ & $\mathrm{k} \ell /$ person per year & $\begin{array}{l}\text { Potential to use local skills for } \\
\text { construction and O\&M }\end{array}$ & Qualitative \\
\hline $\mathrm{BOD} / \mathrm{COD}$ discharged & $\mathrm{g} /$ person per year & $\begin{array}{l}\text { Complexity of construction and } \\
\text { O\&M }\end{array}$ & Qualitative \\
\hline Impact on eutrophication & $\mathrm{N}$ and $\mathrm{P}, \mathrm{g} /$ person per year & $\begin{array}{l}\text { Compatibility with existing } \\
\text { systems }\end{array}$ & Qualitative \\
\hline $\begin{array}{l}\text { Hazardous substances: heavy } \\
\text { metals, persistent organic } \\
\text { compounds, antibiotics/medical } \\
\text { residues, hormones }\end{array}$ & & Ease of system monitoring & Qualitative \\
\hline Contribution to global warming & $\mathrm{kg}$ of $\mathrm{CO}_{2}$ equivalent/year & Durability/lifetime & Qualitative \\
\hline Odour & Qualitative & \multicolumn{2}{|l|}{ Health and hygiene } \\
\hline Nutrients recovered & $\%$ of incoming & Risk of infection & Risk assessment or qualitative \\
\hline Organic material recovered & $\%$ of incoming & $\begin{array}{l}\text { Risk of exposure to toxic } \\
\text { substances }\end{array}$ & Risk assessment or qualitative \\
\hline Energy recovered & $\%$ of system consumption & \multicolumn{2}{|l|}{ Socio-cultural } \\
\hline Water recovered & $\%$ of system consumption & $\begin{array}{l}\text { Willingness to pay (\% of available } \\
\text { income) }\end{array}$ & Cost/person per year \\
\hline \multicolumn{2}{|l|}{ Economic } & $\begin{array}{l}\text { Convenience (comfort, per- } \\
\text { sonal security, smell, noise, } \\
\text { attractiveness) }\end{array}$ & Qualitative \\
\hline $\begin{array}{l}\text { Annual costs (use lifecycle cost } \\
\text { approach) }\end{array}$ & Cost/person per year & Institutional requirements & Qualitative \\
\hline $\begin{array}{l}\text { User capacity to pay (\% of avail- } \\
\text { able income) })^{*}\end{array}$ & Disposable income/person & Responsibility distribution & $\begin{array}{l}\text { Definition of level of organisa- } \\
\text { tion (household, settlement, } \\
\text { municipality) }\end{array}$ \\
\hline Local development potential & Qualitative & Current legal acceptability & Qualitative \\
\hline \multirow[t]{3}{*}{$\begin{array}{l}\text { Time required by users for } \\
\text { maintenance }\end{array}$} & Hours/person per year & $\begin{array}{l}\text { Appropriateness to current local } \\
\text { cultural context }\end{array}$ & Qualitative \\
\hline & & $\begin{array}{l}\text { System perception (including } \\
\text { towards reuse of waste) }\end{array}$ & Qualitative \\
\hline & & $\begin{array}{l}\text { Ability to address awareness and } \\
\text { information needs }\end{array}$ & Qualitative \\
\hline
\end{tabular}

${ }^{*}$ In South Africa, informal settlement users typically do not pay for water and sanitation services although backyard dwellers in formal settlements may do so. 


\begin{tabular}{|l|l|}
\hline \multicolumn{2}{|c|}{$\begin{array}{c}\text { TABLE } 2 \\
\text { Summary of data collected }\end{array}$} \\
\hline Data collected & Application \\
\hline Literature review & $\begin{array}{l}\text { Policy context for sanitation provision, and background information on the environmental, demographic, } \\
\text { and institutional characteristics of the city }\end{array}$ \\
\hline Field observations & \\
\hline Field notes & Providing context for lived reality in informal settlements, and environmental conditions \\
\hline Photographs & Visual aid for detailed description of conditions in informal settlements \\
\hline Interviews & \\
\hline Informal conversations & Supplementary information mentioned outside of interviews \\
\hline Semi-structured interviews & Perspectives and priorities of sanitation professionals \\
\hline Surveys & \\
\hline Survey of taps and toilets & Providing numbers and status of facilities \\
\hline GIS data & Providing location, spatial distribution and status of facilities \\
\hline
\end{tabular}

development, and to make preliminary recommendations for addressing some of the challenges. The research objectives were:

- Provide definitions of sustainability and equity as they pertain to sanitation, and suggest potential measures for assessing the sustainability and equity of sanitation services

- Identify which dimensions of sustainability and equity are the most salient amongst sanitation professionals who are involved with planning or providing sanitation services in informal areas

- Describe and highlight on-the-ground challenges of providing sanitation services to informal settlements at a micro level, which can assist stakeholders in getting a better understanding of inter-related challenges.

This research focused on the City of Cape Town. While parallels may be drawn to informal settlements in other cities and towns, there are likely to be context-specific issues which will vary across different municipalities.

\section{METHODS}

\section{Data collection and literature review}

Interviews were conducted in order to get a better understanding of the knowledge, opinions and experience of stakeholders involved with decision-making and steering the development of sanitation services. Twenty-three unstructured interviews, using sustainability and equity as themes, were conducted with various stakeholders: 2 from provincial government, 11 from local government, 1 in academia, 7 non-governmental organisation (NGO) workers, and 2 entrepreneurs. A 'snowball sampling' method (Morgan, 2008) was employed to expand the network of interviewees from initial contacts. In addition to the unstructured interviews, informal conversations with residents of informal settlements, and field observations in 4 informal settlements in Cape Town helped contextualise perspectives, priorities, and barriers to sustainability and equity in the implementation of sanitation services. The interviews and field notes were transcribed and disaggregated into identifiable sanitation problems and causal relationships (Roe, 1994), using Microsoft Office OneNote to tag categories relating to sustainability and equity of sanitation services, with broad categories around institutions, politics and governance, environment, health, social, and economic issues with sub-categories, e.g. cost, design, safety and participation.

A literature review was conducted of policy documents pertaining to water and sanitation services, of national and municipal assessment tools such as the Green Drop and Blue Drop certification programmes, and the municipal corporate scorecard, to provide information on the policy context for sanitation provision in the city as a whole, and for informal settlements in particular. In addition, reports, GIS data and 'tap and toilet count' survey data provided by the City of Cape Town (CCT) water and sanitation department were examined to provide an overview of the current status of sanitation services for informal areas in Cape Town. A summary of the data collected, and its application is provided in Table 2 .

\section{Analysis}

Conceptual maps can provide a way to integrate information visualisation with knowledge acquisition and sharing (Cañas et al., 2005), and have been used for 'illustrating relations, identifying patterns, [and] presenting an overview and details' (Tiberghien et al., 2011:461) of complex issues arising in water and sanitation projects. The tagged statements from the interviews were used to construct a conceptual map as a way to visualise the information provided from the field observations and interviews, and to show relationships between key issues emerging around different dimensions of sustainability and equity in sanitation services and factors influencing its development in informal areas. The interview and field data were also compared against the policy review to see where the priorities of sanitation professionals align and diverge, and to develop recommendations for improving sanitation services through the integration of sustainability and equity criteria in planning, implementation, monitoring and evaluation stages. 


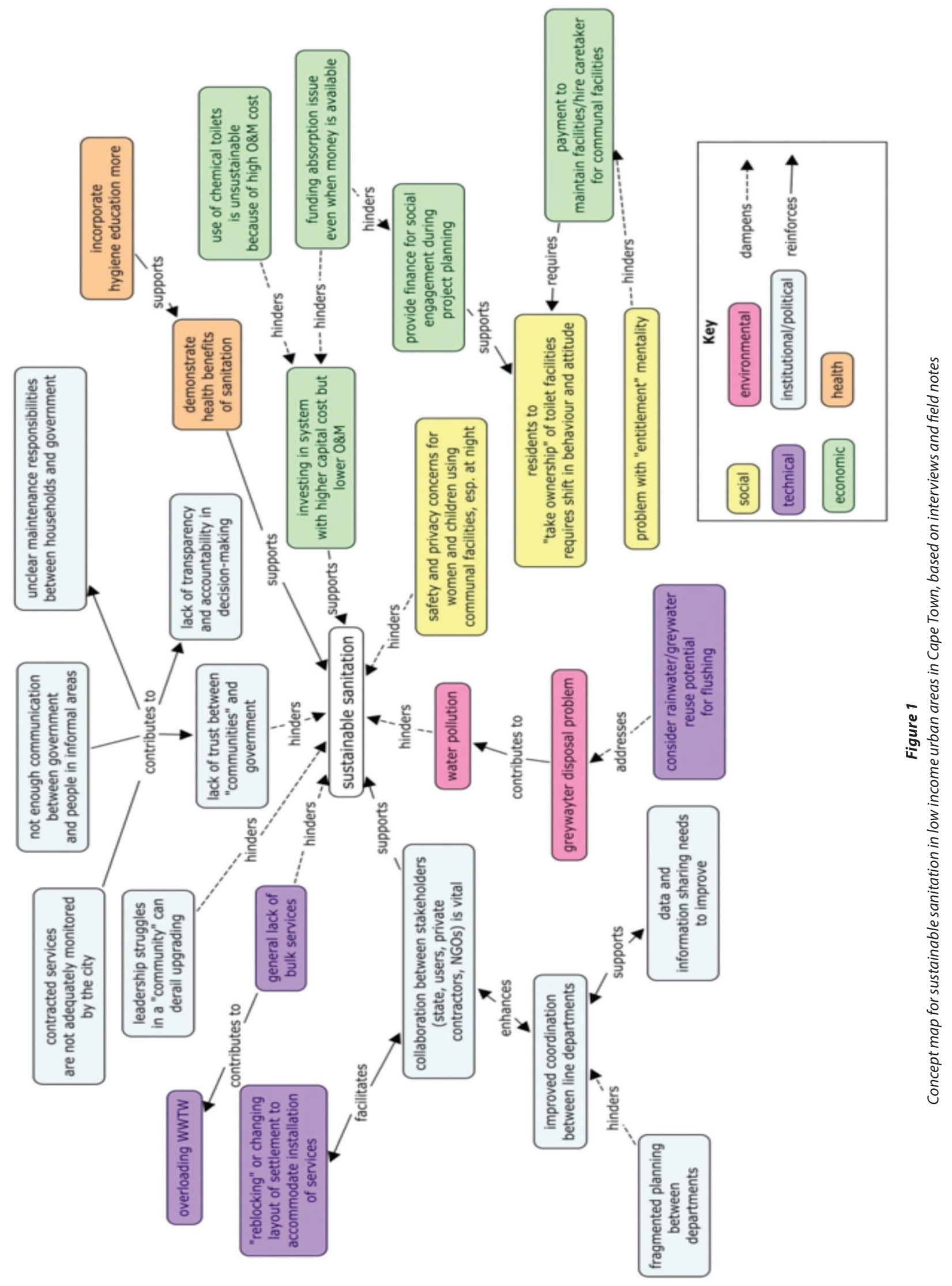




\section{RESULTS}

\section{Sustainability 'situation analysis'}

One of the key points relating to institutions that emerged from the interviews was that because sanitation planning requires coordination between a number of departments (water and sanitation, solid waste, human settlements, roads and stormwater, environmental health) there can be an issue with accountability around decision-making as well as communication between departments. A related issue is the inadequate flow of information both between municipal departments, and externally to residents receiving services, or NGO and private sector 'partners', which undermines trust between residents and local government. These relationships are highlighted in the top left of Fig. 1. Two city officials, however, did mention that the urbanisation department was working to improve coordination between various line departments as part of an umbrella 'urbanisation strategy', although how effective the strategy will be still needs to be determined. Of the different dimensions of sustainability mentioned by interviewees, institutional and economic issues, such as lack of communication and information sharing between stakeholder groups, and inadequate funding for operations and maintenance $(\mathrm{O} \& \mathrm{M})$ were indicated as the most critical to address in trying to achieve sustainable sanitation services. One of the city officials interviewed described a divergence between national policy and practice. The national policy outlined in the Strategic Framework for Water Services stipulates that a basic sanitation service should be 'easily accessible' and sustainably operated (DWAF, 2003). As highlighted, however, by the official, that often is not the case due to some of the challenges highlighted in Fig. 1.

That is the constitution, the legislation, but
we don't do that, we've got all our chemi-
cal toilets. It's access to sanitation, but it's
not a sustainable service... It's not because
we don't want to do it. It's because we're
prevented from doing it due to some of the
circumstances which I mentioned earlier, but
definitely I think more can be done.
(City official)

Some of the 'circumstances' mentioned earlier related to space constraints within informal settlements as well as institutional challenges of coordinating projects and programmes between different departments. A strategy that the CCT is employing to address space constraints and to foster engagement between local government and residents is 're-blocking', which is being facilitated by the NGO, the Community Organisation Resource Centre (CORC). Re-blocking involves mapping and self-enumeration, i.e. a household census of a settlement, taken by residents themselves with the assistance of the NGO, with the objective of changing the spatial layout of the settlement to create more space to install services, improve accessibility, reduce fire hazards and improve safety (CCT, 2013b). Although re-blocking is a useful strategy there are limitations to the scale at which it can be applied, and its applicability in areas deemed unsuitable (by the CCT) for in situ upgrading.

An unresolved and politicised question relating to the overall sustainability of the service is whether or not there are upgrading or relocation plans for a particular settlement, and how that influences the planning and design of sanitation services. Planning is a major challenge, given the dynamic nature of informal settlements as well as demands that extend beyond a single department's control, whether those demands come from other municipal departments, other spheres of government, politicians or residents. As indicated by one city official:

We've got a budget, and we've got a target.
What happens in between, yeah. So if you
cannot reach the target, you know, then the
question is why not. But because you cannot
plan, it's difficult to say what you are going
to reach 3000 toilets. Now what we do now
is we use the portable flush toilets to make up
the difference.
(City official)

In addition to institutional issues, there were economic concerns (green boxes in Fig. 1). For instance, the high O\&M costs associated with chemical and other toilets, e.g. portable flush and container toilets, which require daily or weekly emptying, were flagged as a barrier to sustainability. Also, the focus on ensuring that a designated number of toilets are provided in a given financial year limits the extent to which municipal officials incorporate sustainability considerations into planning sanitation services.

One of the major technical challenges (purple boxes in Fig. 1) identified for expanding services in informal settlements is the general lack of bulk water and sewer services to connect to, particularly in peri-urban areas, which have characteristics of both urban and rural land use, and are usually on the outskirts of urban centres. Currently, $74 \%$ of the sanitation facilities in informal settlements in Cape Town are non-sewered, on-site systems (CCT, 2014); thus, managing grey-water to prevent water pollution was the main environmental concern raised by interviewees. Cape Town has the additional challenge of having a high water table in many areas, which means that on-site grey-water disposal systems such as soakaways have a great potential to pollute ground or surface water, and given the high density of most settlements, may easily be overloaded. One city official suggested the potential to use grey-water for flushing toilets, but added that there were social acceptance issues, related to service inequities, with regards to using grey-water for pour-flush toilets. Pour-flush toilets are similar to conventional flush toilets except that instead of water coming from a cistern above the bowl, users must pour water into the bowl to flush it.

For example we've attempted pour flush,
but people say we don't want to [use] our
dishwater [for flushing purposes]. There's a
lack of education, and I don't think maybe
we're getting our education right, but again
it's for people with low income trying to reuse
grey-water
(City official)

The lack of bulk services to connect to, and drainage problems, are issues that could be considered inherent to the nature of informal settlements, given the social and economic circumstances under which informal settlements develop, as well as where most of them are located, which will be discussed in the next section.

Another technical issue is ineffective use of capacity at wastewater treatment works (WWTW) since currently only one of the city's 22 WWTW plants, Borcherds Quarry, is used to treat the faecal sludge from all of the non-sewered sanitation systems; 

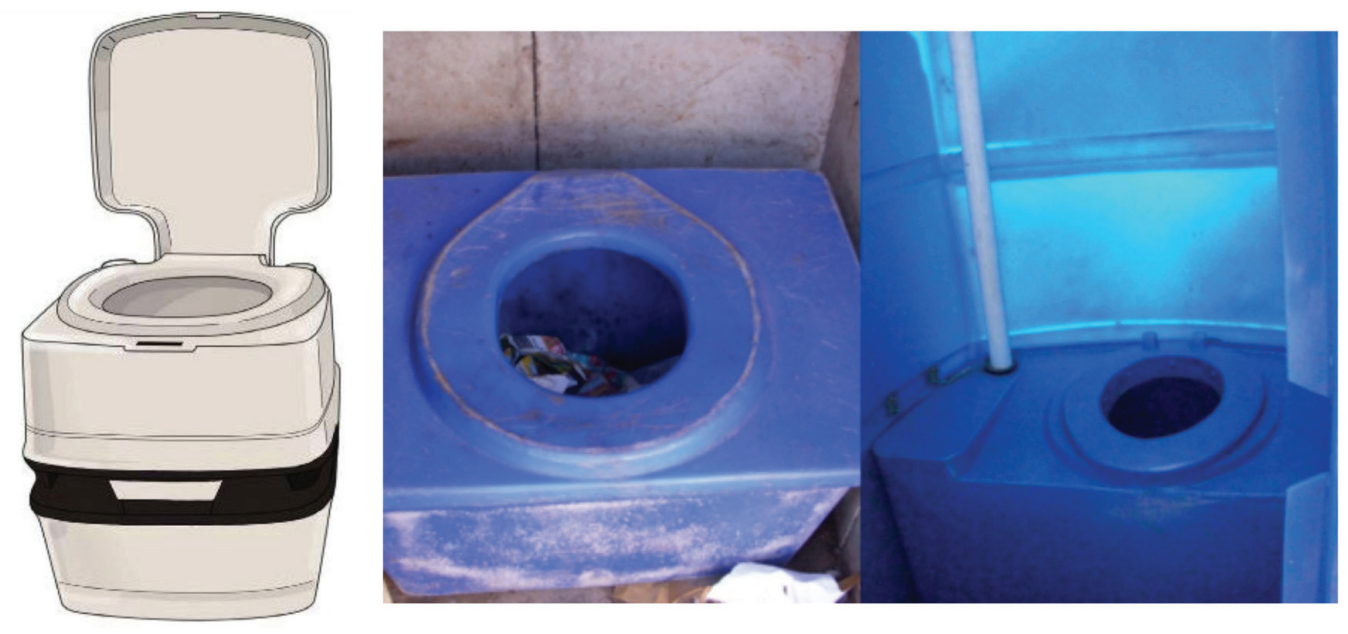

Figure 2

Portable flush (Zille, 2013), container and chemical toilets used in Cape Town

examples of non-sewered systems are shown in Fig. 2, (29 676 units), $95 \%$ or 28144 of which need to be emptied and cleaned, weekly or oftentimes even more frequently (CCT, 2014). While this allows for centralised control, it also creates service backlogs at the WWTW given the sheer number of units that need to be emptied and cleaned, weekly or oftentimes even more frequently. The reliance on mainly on-site 'emergency' systems as an interim solution relates to attitudes expressed by multiple government officials interviewed, vacillating between acknowledging a responsibility to service informal settlements, needing to discourage their growth, and considering settlements as temporary until people are relocated to housing projects or the settlements are 'formalised' through in situ upgrading.

A major social concern related to the need to consider the safety of women and children. The distance required to walk to communal facilities often discourages them from using the facilities at night and during the early hours of the morning. Barriers to accessing sanitation facilities are discussed further in the next section.

\section{Equity 'situation analysis'}

Many of the social and economic issues mentioned as challenges to sustainable sanitation intertwine with equity issues, but there are also distinctive issues. For purposes of clarity, equity concepts were limited to those relating to access, resource allocation and perceptions (Fig. 3). Inequities in access, mentioned by interviewees, ranged from social to technical to economic issues.

Access to communal toilet facilities can be a contentious issue, and toilet facilities are sometimes commandeered for 'private' use. As one city official stated:

The shebeen owner would close, would put a padlock and nobody else except the customers (would) have access... or near the taxi rank you'll find that the taxi owners actually take up and say these ablutions are going to be used by the staff and so forth. (City official)

This issue also relates to inequities in the distribution of toilet facilities throughout a settlement. In some areas, access routes are too narrow for 'honeysuckers' (vacuum tankers) to enter. As a result, contractors place the toilets in rows along the widest access route or on the perimeter of a settlement, which may be difficult to reach for people living in the interior of settlements (Fig. 4). Another challenge is that when settlements are on private land, the CCT is legally prohibited from installing services on the property. Therefore, toilet facilities are only permitted on the perimeter of the settlement.

In addition to distribution issues, access can also be limited for users who have physical disabilities, or are elderly and unable to walk long distances. Night time access is also limited, given safety concerns as mentioned in the previous section. Subsidies are available to cover the extra costs associated with facilities for disabled people who qualify for housing subsidies (PGWC, 2013), but often, in the context of informal settlements, there are so many other challenges that incorporating designs for people with special needs is overlooked, as illustrated in the following dialogue with a CCT official:

City official: And now that is for me I don't know, sometimes, for me if that is going to be insisted I'd actually say give me a break.

Interviewer: It's almost too much.

City official: Let me first put in 200, give me, let me first put in 200 that don't have, and see if that's going to work because we don't even know if that's going to work, let alone providing 5, 10 or 50 facilities for disabled people.

Efficient use of resources is also a consideration, and standardised designs are easier to implement. However, as the demand for facilities which can accommodate diverse needs grows, then greater attention will have to be given to access for vulnerable people (women, children, disabled, and elderly) (Hutton et al., 2008).

How to allocate resources equitably is an essential question for any aspect of governance, including for sanitation services. The 1994 White Paper on Water Supply and Sanitation promoted the underlying equity principle of 'some for all - not all for some' (DWAF, 1994), and this is echoed in the national government's commitment to 'free basic water services' which was added in a draft 2002 White Paper, Water is Life, Sanitation is Dignity (DWAF, 2002). Various grants exist for funding basic services for indigent households. These include the 


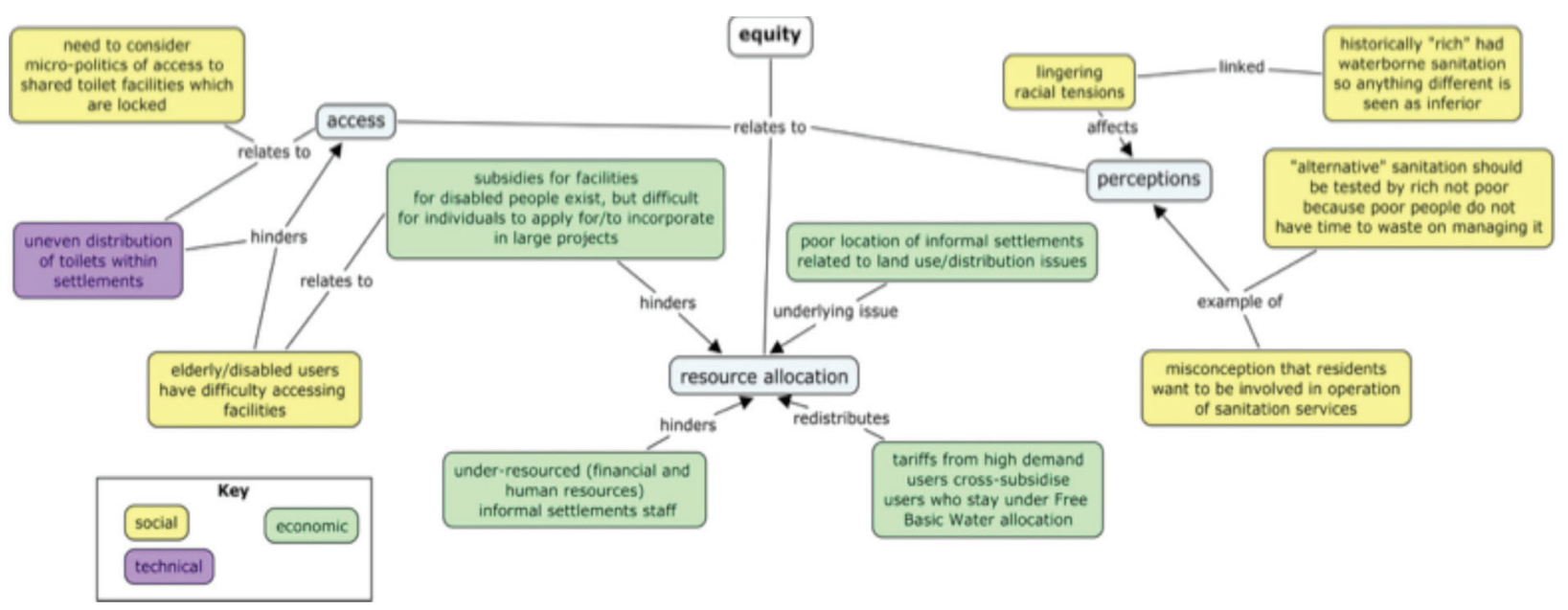

Figure 3

Equity concept map for sanitation services in Cape Town, based on field notes and interviews

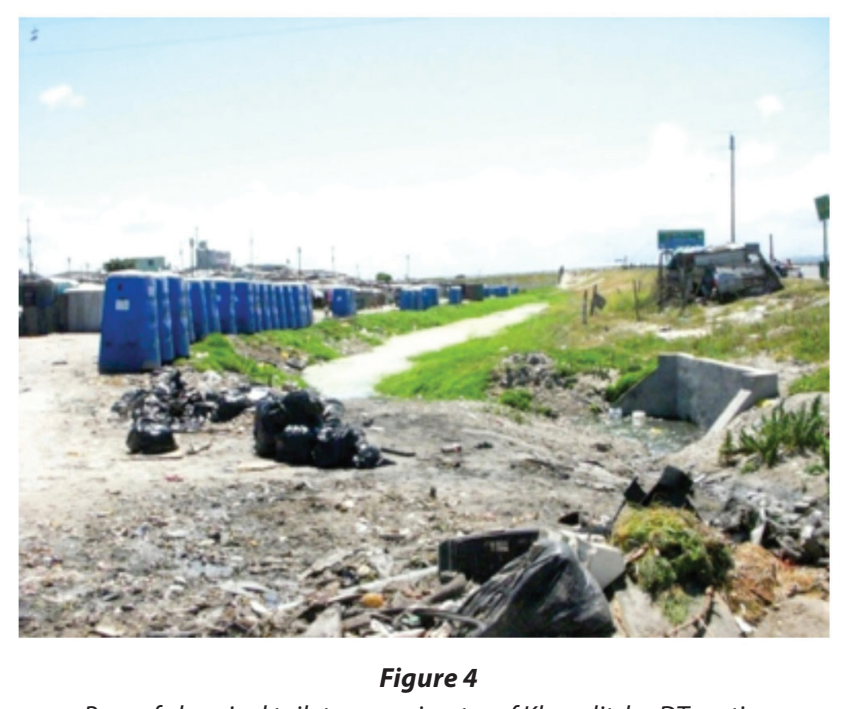

Row of chemical toilets on perimeter of Khayelitsha DT section

Equitable Share (ES), which is an unconditional grant administered by the Department of Cooperative Governance and Traditional Affairs, and the Urban Settlements Development Grant (USDG), which is a conditional grant administered by the National Department of Human Settlements for capital investments to improve service delivery to urban low-income households. The USDG is used to cover capital costs for installing services, and some of the ES can be used for ongoing O\&M costs, but the rest needs to come from other revenue sources.

One of the equity concerns linked to sustainability concerns is the issue of paying for O\&M. Since most grants are designated for capital costs, the CCT mainly uses municipal revenue to cover the cost of O\&M of water and sanitation services. There is, however, the question of how much of a sanitation service should be subsidised. With water, the volume of 6 $\mathrm{k} \ell$ of free water was set, based on a minimum recommendation of $25 \ell$ per day for an 8-person household (DWAF, 2001). This amount correlates with 4.2 kilolitres of sewage covered (sewage is calculated as $70 \%$ of water consumption in CCT), but for non-sewered sanitation systems what should be covered is more subjective. The use of 'alternative' sanitation systems, i.e., any system other than a conventional waterborne system brings its own set of issues and in many cases, is viewed as 'undignified' or 'inferior' (Anon., 2005; Matsebe and Osman, 2012). As observed by a city official, 'Certainly what has come out of our interaction with communities over the years is that people want waterborne sewage one-on-one. Whether we, as a city, like it or not, we've got to listen, and see how we can provide these services.' The sustainability of providing individual household waterborne sewerage as part of a Free Basic Sanitation policy, as compared to the inequity of providing different levels of sanitation service and alternative sanitation options to low-income households still needs to be publicly discussed and debated. As another city official cautioned, 'It's not equity, it's getting a cheaper solution for poor people, so it's almost like reinforcing the gap.'

The location of many informal settlements makes it difficult to provide water and sanitation services, given either the distance from existing bulk infrastructure, or location on marginal land deemed unsuitable for residential development (road and rail reserves, wetlands, flood- prone areas, landfills, etc.). Furthermore, there is a clear tension between the mandate for local government to provide basic services and the sentiment that informal settlements should not exist (Huchzermeyer, 2009). Historical inequities in the spatial layout of the city, based on apartheid planning as well as Cape Town's natural boundaries - the Atlantic Ocean and Table Mountain - make relocation of settlements to well-located land closer to economic opportunities and existing infrastructure a challenge, given limited space and high land costs. As pinpointed by one of the NGO workers:

\section{If you want to address the issue of equity and those kinds of things, the first issue is of land distribution, and I don't think you, do you tackle that issue? I don't think this problem is going to go away, and there's no easy way of tackling that issue now either so (sigh) I don't know what the solution is... \\ (NGO worker)}

\section{DISCUSSION}

The results indicate that there is awareness amongst practitioners that the current practice of providing 'temporary' sanitation facilities, such as chemical or container toilets, which end up 
becoming 'temporary permanent' services, is unsustainable. Furthermore, there is also acknowledgment that differentiating the services provided for informal areas from the services provided to formal areas may contribute to further inequities in the city, given the existing spatial inequalities and if care is not taken to consciously incorporate informal settlements into infrastructure development plans. Translating awareness of shortcomings into planning, implementation and monitoring practices on a wide scale will not happen overnight nor is it likely to address all of the sustainability and equity issues raised by interviewees. Significant decisions around aspects of sustainability and equity may have been made outside of the control of the individuals interviewed, underscoring the need to consider sustainability and equity in sanitation at different levels of decision-making.

There are methods and tools which can assist in moving towards sustainability and equity in sanitation services for informal areas, at various levels of decision-making and different stages of sanitation projects. These methods and tools would be particularly useful to incorporate during the planning and design stages when there is the greatest potential to influence decision-making related to prioritisation of sanitation problems, sanitation technology options, layout and numbers of toilets delivered.

The CCT human settlements department is developing a 'development matrix', which will be used to guide the city's strategy towards the upgrading of informal settlements (CCT, 2013b), which in turn will influence the type of sanitation system selected. Settlements are being categorised according to a variety of physical, technical and environmental risk factors which determine the ability to upgrade in situ or the need for relocation. The development of such a tool and strategy for informal settlements presents both an opportunity to develop a long-term, rather than an ad hoc, approach to the provision of sanitation services, but also a risk of reinforcing top-down planning strategies which exclude non-government stakeholders. Thus, the development matrix as a planning tool should be used in conjunction with various planning approaches which are more inclusive, given that planning and design experts are often in a different socio-economic group and live in a different environment from residents in informal settlements, limiting their ability to relate to circumstances in informal settlements, which may hamper the overall success of the sanitation system (McConville, 2012).

The Community-Led Urban Environmental Sanitation (CLUES) method of planning, developed by the Environmental Sanitation Working Group of the Water Supply and Sanitation Collaborative Council, promotes multi-stakeholder participation in a 7-step format (Lüthi et al., 2011) and shares some similarities with the more wellknown Community-Led Total Sanitation (CLTS) approach, such as an emphasis on the need to create demand for sanitation services, and 'process ignition' (in the case of CLUES) or 'triggering' (in the case of CLTS) demand for sanitation as a first step. Additionally, the first 5 steps place great emphasis on fostering communication between stakeholders and getting a detailed understanding of the sanitation priorities and needs of 'community' members (residents of a given settlement) through surveys, mapping and stakeholder analysis. Although not a panacea, the CLUES method may be particularly useful in providing guidelines for addressing some of the institutional issues raised in the results section. The re-blocking approach that the CCT has adopted as one method for in situ upgrading also shares many similarities with the CLUES method, but with a greater emphasis on spatial reconfiguration and less on the selection and design of a specific system. The two methods could potentially be used complementarily to enable greater participation from varied stakeholders and incorporate sustainability and equity assessment criteria prior to the selection of a sanitation system.

Part of the reason that sustainability and equity criteria are not assessed may be because many proposed sustainability indicators would be difficult to measure or are relatively subjective indicators, e.g. contribution to climate change or odour (Kvarnström et al., 2004). Other indicators, such as annual costs for capital and operating expenditures, are usually measured, but need to be tempered by consideration of other indicators such as risk of exposure to hazardous substances and social acceptability. Equity indicators beyond resource allocation are less well-defined, although one potential measure which could supplement the current measure of the ratio of toilets to households would be to calculate the percentage of households that have to walk farther than a pre-defined distance to access a facility (for water standpipes, the CCT's standard is less than $100 \mathrm{~m}$ ) or the amount of time required to maintain different sanitation technologies. The criteria which should be assessed are context specific and should be tailored to reflect major issues arising in informal areas, such as safety of women and children and grey-water management.

The question then arises as to who will be responsible for incorporating sustainability and equity considerations into sanitation servicing for informal areas? Furthermore, how will responsibilities be delegated at different levels: household, ward, city (municipality), and beyond the city, which is the classification of domains used by the International Water Association (IWA, 2006). At present, responsibility for the provision of sanitation services in informal settlements is shared mainly between: the CCT human settlements informal settlements department (planning and implementation for housing projects), the water and sanitation department (delivering 'interim' services and O\&M of existing services), the solid waste department (collection of solid waste), and the environmental health department (monitoring the potential health risks at water and sanitation facilities).

In addition to municipal departments, other stakeholders should also have a role in ensuring that sustainability and equity criteria for sanitation are considered. Informal settlement residents should have a role in selecting viable sanitation options and be informed of any operational and maintenance requirements (Lüthi et al., 2011). NGOs and community-based organisations (CBOs) are well positioned to act as monitors, and potentially also as service providers, although this occurs less commonly in South Africa than in other developing countries. Contractors who provide sanitation services to informal settlements need to be monitored, both by municipal officials and residents. The sanitation products sold and services rendered could be assessed and regulated, e.g. a certification scheme could be implemented which recognises providers who meet specific criteria, as part of a wider effort to move towards 'green infrastructure', which would create an incentive for contractors to incorporate sustainable practices. Although other stakeholders also have important roles to play, given the current institutional arrangements in South African cities, it is likely that 'the state', in the form of local government, will continue to have the most control over the direction of sanitation service development. As such it is important to have 'champions' within local government, at city level, to advocate for improving sanitation services in informal areas. 
At national level, a national strategy or policy, such as the proposed update to the White Paper on Water and Sanitation Policy that explicitly includes specific measures for sustainability and equity of sanitation services, can influence how sanitation services are developed in both informal and formal areas of cities. Equity can be influenced by, for example, explicit requirements to include a certain percentage of toilets that are accessible to disabled and elderly people in public or communal facilities in informal areas, or to include such toilets on an asneeded basis following a needs assessment.

\section{CONCLUSIONS}

Integrating sustainability and equity considerations into sanitation services for informal areas will not be easy given the many dimensions that need to be considered as well as the numerous barriers, some of which were outlined in this paper. Nevertheless, given the importance of sanitation to both human health and environmental quality (Hutton and Bartram, 2008), and the emphasis on sanitation as 'dignity' in South Africa (DWAF, 2002), ensuring that sanitation services are sustainable and equitable is essential. An important area for further research is to try and identify at what level in the decision-making processes, and by whom, equity and sustainability issues can best be addressed. Institutional and economic barriers may pose some of the biggest hurdles, as suggested by this research, but also are likely to have the most leverage to convince all stakeholders to integrate sustainability and equity principles into every stage of sanitation service delivery.

\section{ACKNOWLEDGMENTS}

The research which supported this paper was funded by UNESCO-IHE, which received grant funding from the Bill and Melinda Gates Foundation as part of a multi-institutional research project entitled 'Stimulating Local Innovation on Sanitation for the Urban Poor in Sub-Saharan Africa and Southeast Asia'.

\section{REFERENCES}

ANON. (2005) Ecosan: In search of a sustainable sanitation solution. The Water Wheel 4 (4) July/August 2005) 22-24. URL: http:// www.wrc.org.za/Knowledge Hub Documents/Water Wheel/ Articles/2005/04/WaterWheel_2005_04_Ecosan p22-24.pdf (Accessed 13 February 2014).

BALKEMA A, PREISIG H, OTTERPOHL R and LAMBERT F (2002) Indicators for the sustainability assessment of wastewater treatment systems. Urban Water 4 153-161.

CAÑAS AJ, CARFF R, HILL G, CARVAHLO M, ARGUEDAS M, ESKRIDGE TC, LOTT J and CARVAJAL R (2005) Concept maps: Integrating knowledge and information visualization. In Knowledge and Information Visualization. Springer, Berlin.

CCT (CITY OF CAPE TOWN) (2013a) Draft five year corporate scorecard 2012/13 to 2016/17 (2013/14 year ) including proposed adjustments. City of Cape Town, Cape Town. 1-6.

CCT (CITY OF CAPE TOWN) (2013b) Informal settlements development matrix. (Powerpoint presentation) Presented at the sub-council 4 meeting on 24 October 2013. City of Cape Town, Cape Town.

CCT (CITY OF CAPE TOWN) (2014) Infrastructure asset management plan: Informal settlements strategic overview and five year plan 2013-2014 Volume 5 (unpublished) City of Cape Town, Water and Sanitation Department, Cape Town.

DWAF (DEPARTMENT OF WATER AFFAIRS AND FORESTRY, SOUTH AFRICA) (1994) Water Supply and Sanitation Policy White Paper. Department of Water Affairs and Forestry, Pretoria.

DWAF (DEPARTMENT OF WATER AFFAIRS AND FORESTRY,
SOUTH AFRICA) (2001) Free Basic Water Implementation Strategy document. Version 1. Department of Water Affairs and Forestry, Pretoria.

DWAF (DEPARTMENT OF WATER AFFAIRS AND FORESTRY, SOUTH AFRICA) (2002) Water is Life, Sanitation is Dignity. Draft White Paper. Department of Water Affairs and Forestry, Pretoria.

DWAF (DEPARTMENT OF WATER AFFAIRS AND FORESTRY, SOUTH AFRICA) (2003) Strategic Framework for Water Services: Water is Life, Sanitation is Dignity. Department of Water Affairs and Forestry, Pretoria. URL: http://www.dwaf.gov.za/Documents/ Policies/Strategic\%20Framework\%20approved.pdf (Accessed 13 September 2012).

DWAF (DEPARTMENT OF WATER AFFAIRS AND FORESTRY, SOUTH AFRICA) (2008) Free Basic Sanitation Implementation Strategy. Department of Water Affairs and Forestry, Pretoria.

EAWAG (SWISS FEDERAL INSTITUTE FOR ENVIRONMENTAL SCIENCE AND TECHNOLOGY) and SANDEC (EAWAG DEPARTMENT OF WATER AND SANITATION IN DEVELOPING COUNTRIES) (2000) Summary report of Bellagio expert consultation on environmental sanitation in the 21st century, Bellagio. Eawag/Sandec, Switzerland.

FREEMAN M, ERHARD L, FEHR A and OGDEN S (2011) Equity of access to WASH in schools. URL: http://www.unicef.org/wash/ schools/files/Equity_of_Access_to_WASH_in_Schools(1).pdf (Accessed 28 April 2013).

HELLSTRÖM D, JEPPSSON U and KÄRRMAN E (2000) A framework for systems analysis of sustainable urban water management. Environ. Impact Asses. 20 311-321.

HUCHZERMEYER M (2009) The struggle for in situ upgrading of informal settlements: a reflection on cases in Gauteng. Dev. S. Afr. 26 (1) $59-73$.

HUTTON G and BARTRAM J (2008) Global costs of attaining the millennium development goal for water supply and sanitation. Bull. World Health Organ. 86 13-19.

HUTTON G, RODRIGUEZ UE, NAPITUPULU L, THANG P and KOV P (2008) Economic Impacts of Sanitation in Southeast Asia. World Bank: Water and Sanitation Program, Jakarta.

IWA (2006) Sanitation 21: Simple approaches to complex sanitation, a draft framework for analysis. IWA, London.

KVARNSTRÖM E, BRACKEN P and YSUNZA A (2004) Sustainability criteria in sanitation planning. In: Proceedings of the 30th WEDC International Conference, October 2004, Vientiane, Lao PDR, 104-107. URL: http://wedc.lboro.ac.uk/resources/conference/30/ Kvarnstrom.pdf (Accessed 14 September 2013).

LÜTHI C, MOREL A, TILLEY E and ULRICH L (2011) CommunityLed Urban Environmental Sanitation Planning: CLUES. EawagSandec; WSSCC; UN-HABITAT. URL: http://www.sswm.info/ sites/default/files/reference_attachments/LUETHI\%20et\%20al\%20 2011\%20CLUES.pdf (Accessed 9 July 2012).

MATSEBE G and OSMAN A (2012) Ecological sanitation in urban South Africa: socio-cultural, design and operational challenges of urine diversion dry (UDD) toilets and the impact on users' perceptions. In: $4^{\text {th }}$ International Dry Toilet Conference, 22-24 August 2012, Tampere, Finland.

McCONVILLE JR (2012) Participation in sanitation planning in Burkina Faso: Theory and practice. J. Water Sanit. Hyg. Dev. 4 (2) 304-312.

MORGAN DL (2008) Snowball sampling. In: The SAGE Encyclopedia of Qualitative Research Methods. Sage Publications, 816-817. URL: http:// dx.doi.org /10.4135/9781412963909 (Accessed 10 February 2014).

MOVIK S and MEHTA L (2010) The Dynamics and Sustainability of Community-led Total Sanitation (CLTS): Mapping challenges and pathways. STEPS Working Paper 37, STEPS Centre, Brighton. URL: http://sanitationupdates.files.wordpress.com/2011/01/clts-steps 2010.pdf (Accessed 9 September 2013).

PGWC (PROVINCIAL GOVERNMENT OF THE WESTERN CAPE) (2003) Informal Settlements Handbook. Introduction. Provincial Government of the Western Cape, Cape Town. URL: http://www. westerncape.gov.za/eng/pubs/guides/I/10448 (Accessed 8 July 2013).

PGWC (PROVINCIAL GOVERNMENT OF THE WESTERN CAPE) (2013) Individual housing subsidies. Provincial Government of the Western Cape, Cape Town. URL: http://www.westerncape.gov.za/ 
service/individual-housing-subsidies (Accessed 12 February 2014). ROE E (1994) Narrative Policy Analysis: Theory and Practice. Duke University Press, Durham.

ROSEMARIN A, EKANE N, CALDWELL I, KVARNSTRÖM E, McCONVILLE JR, RUBEN C and FOGDE M (2008) Pathways for Sustainable Sanitation: Achieving the Millennium Development Goals. IWA Publishing, London.

SCOTT V, MATHEWS V and GILSON L (2012) Constraints to implementing an equity-promoting staff allocation policy: understanding mid-level managers' and nurses' perspectives affecting implementation in South Africa. Health Policy Plann. 27 (2) 138-46. URL: http://www.ncbi.nlm.nih.gov/pubmed /21450839 (Accessed 25 April 2013).

STATS SA (STATISTICS SOUTH AFRICA) (2010) GHS Series Volume III, Water and sanitation 2002-2010: In-depth analysis of the General Household Survey data. Statistics South Africa, Pretoria. 69 pp.
SUSANA (2014) Sustainable Sanitation Alliance: Introduction of sustainable sanitation. URL: http://susana.org/lang-en/sustainablesanitation (Accessed 22 January 2014).

TIBERGHIEN JE, ROBBINS PT and TYRREL SF (2011) Reflexive assessment of practical and holistic sanitation development tools using the rural and peri-urban case of Mexico. J. Environ. Manage. 92 (3) 457-471. URL: http://www.ncbi.nlm.nih.gov/pubmed/21074314 (Accessed 17 July 2012).

WHO (WORLD HEALTH ORGANISATION) and UNICEF (UNITED NATIONS CHILDREN'S FUND) (2013) Progress on Sanitation and Drinking-Water 2013 Update. WHO and UNICEF, Geneva. ZILLE H (2013) The politics behind the "toilet wars". SA Today. URL: http://www.politicsweb.co.za/politicsweb/view/politicsweb/en/pag e71619?oid $=383760$ andsn=Detailandpid $=71619$ (Accessed 17 July 2013). 